\title{
BIOÉTICA, SALUD MENTAL Y GÉNERO
}

\section{Carmen Bravo de Rueda Ortega*}

Resumen: Este artículo enfoca el desarrollo de tres importantes conceptos, propios de nuestra era, cuya definición y alcance inicial han cambiado en los últimos años: bioética, salud mental y género. Analiza su interrelación, utilizando datos del estudio epidemiológico hecho en Lima, Perú, por el Instituto Nacional de Salud Mental en "mujeres unidas".

Palabras clave: bioética, salud mental, mujer, género

\section{BIOETHICS, MENTAL HEALTH CARE AND GENDER}

\begin{abstract}
This paper focuses on the development of three main concepts, representing our time, whose definition and initial impact has changed in the last years: bioethics, mental health care and gender. It analyzes their interrelationship using data from the epidemiological research carried out in Lima, Peru, by the National Institute of Mental Health Care of Woman in "united women"
\end{abstract}

Key words: bioethics, mental health care, woman, gender

\section{BIOÉTICA, SAÚDE MENTAL E GÊNERO}

Resumo: Este artigo enfoca o desenvolvimento de três importantes conceitos, próprios de nosso tempo, cuja definição e alcance inicial mudaram nos últimos anos: bioética, saúde mental e gênero. Analisa sua inter-relação, utilizando dados do estudo epidemiológico feito em Lima, Perú, pelo Instituto Ncional de Saúde Mental.

Palavras chave: bioética, saúde mental, mulher, gênero

* Magíster en Psicología Clínica y de Familia (USMP). Presidenta de la Asociación Peruana de Salud Mental para la Mujer. Secretaria de Asociación Peruana de Bioética. Perú

Correspondencia: cbravoderueda@terra.com.pe 


\section{¿Mujer o género?}

Este artículo habla sobre la mujer, su salud mental, su problemática y su relación con la bioética. El concepto "género", aunque muy utilizado en los últimos tiempos, todavía genera ciertas confusiones, por eso creemos importante explicarlo previamente.

Hay un abismo entre el concepto "mujer", que predominó en tiempos antiguos, y el concepto "género" empleado en la actualidad, aunque algunas implicancias todavía no se hayan superado. Hurtado(1) señala que el nacimiento de la mujer era desgracia para la tribu, se le encomendaban las labores de bestia de carga, labradora de la tierra, pastora de rebaños, podía cambiar de dueño en la guerra y era cuidadora de enfermos y niños; menciona que, bajo la influencia de la civilización griega, pasó a ser productora de ciudadanos, según su condición social, y luego, con el cristianismo y su desprecio por la carne, llegaron a llamarla "impura" o "hija del demonio". Lo cierto es que siempre fue considerada como un ser inferior $\mathrm{y}$, lamentablemente, esto continúa en algunas sociedades.

El Diccionario de la Real Academia Española define "género" (del latín genus, generis) como "conjunto de seres que tienen uno o varios caracteres comunes (...) Clase o tipo a que pertenecen personas o cosas(2). El género, por tanto, puede usarse tanto para definir a personas de sexo masculino como femenino.

La palabra "género", como se usa actualmente, fue utilizada por las feministas americanas, que deseaban hacer hincapié en las distinciones de tipo social, en lugar de tan sólo en las diferencias biológicas aludidas con el concepto de "sexo". "Fueron las feministas radicales quienes desarrollaron el concepto de género", recalca Kate Millar. "En virtud de las condiciones sociales a que nos hallamos some- tidos, lo femenino y lo masculino constituyen, a ciencia cierta, dos culturas y dos tipos de vivencia radicalmente distintos. El desarrollo de la identidad genérica depende, en el transcurso de la infancia, de la suma de todo aquello que los padres, los compañeros y la cultura en general consideran propio de cada género en lo concerniente al temperamento, al carácter, a los intereses, a la posición, a los méritos, a los gestos y a las expresiones. Cada momento de la vida del niño implica una serie de pautas acerca de cómo tiene que pensar o comportarse para satisfacer las exigencias inherentes al género. Durante la adolescencia se recrudecen los requerimientos de conformismo, desencadenando una crisis que suele templarse y aplacarse en la edad adulta"(3).

Sin embargo, no faltaron quienes se opusieron al enfoque de género. Guerra(4) considera que la definición de la perspectiva de género -respecto de que "las diferencias entre hombres y mujeres responden a una estructura cultural, social y psicológica y no a condiciones biológicas"- es muy radical y deja de lado la base biológica en lo que suele llamarse "femenino o masculino". Según él, "tenemos que constatar que por mujer designamos a un ser cuyo cuerpo se contradistingue del masculino por una serie de rasgos sui géneris", añadiendo que estos conceptos son muy diversificados y complejos dada su base biológica.

En su acepción reciente más simple, "género" es sinónimo de mujeres $(5, p .7)$, aunque hay autores que rechazan categóricamente este concepto. Según $\operatorname{Scott}(5$, p.2), el concepto resalta los aspectos relacionales de las definiciones normativas de la femineidad. Expresa que quienes se preocuparon porque los estudios académicos en torno a las mujeres pudieran centrarse de forma separada y demasiado limitada en ellas, utilizaron el término para introducir una noción relacional en el vocabulario analítico. De acuerdo con esta perspectiva, hombres y 
mujeres fueron definidos el uno en términos del otro, y no se podría conseguir la comprensión de uno u otro mediante estudios completamente separados.

¿Por qué es necesario hacer hincapié sobre la problemática de género? ¿Por qué no basta que se den lineamientos para todas las personas? Tan sólo el hecho de que, por mucho tiempo, haya primado la desigualdad entre hombre y mujer, marginando y poniendo en un plano inferior a esta última, justifica que, en la actualidad, se esté trabajando en los conceptos de equidad de género y se fomente el desarrollo de la mujer y su empoderamiento en todos los roles que desempeña y en las diferentes áreas en las que actúa.

Por otro lado, el enfoque de género permite visualizar la desigual distribución del poder entre varones y mujeres, y la manera en que estas desigualdades son reforzadas por instituciones sociales, jurídicas, religiosas y políticas. En este sentido, esta división dicotómica basada en el género subordina y desvaloriza a las mujeres, recorta oportunidades y crea barreras para la igualdad política, cultural, social y económica. Junto con esta discriminación basada en el género, operan otras formas de subordinación, por ejemplo, de clase social, edad, raza u orientación sexual(6).

\section{Salud mental}

Así como el concepto de "género" ha ido variando a través del tiempo, expandiéndose y abarcando más roles y áreas en las que se desempeñan las personas, también el de "enfermedad mental" ha evolucionado y ha dado paso al concepto de "salud mental".

Al principio, la salud mental estuvo vinculada a la ausencia de enfermedad mental; ha evolucionado y, en este momento, predomina el enfoque de tipo integral que involucra un con- junto de factores de tipo biológico, psicológico y social que incluyen a la persona sana.

Llanos opina que la salud mental corresponde al aspecto sano del individuo en sus dimensiones psicológicas y sociales, a través de las cuales lleva una relación armoniosa con su medio ambiente, lo cual le permite realizar las conductas adecuadas y necesarias para su autoafirmación y autorrealización(7).

En Perú, la salud mental -conceptuada por psiquiatras como Honorio Delgado, con gran influencia del humanismo- contemplaba la importancia de los aspectos psicológicos y ambientales tanto en la génesis de las patologías como al momento del tratamiento. Sin embargo, esto no se veía reflejado en la práctica ni en las políticas de salud. Hace unos pocos años se ha puesto énfasis en la prevención de la enfermedad y en la promoción de la salud, considerando la participación activa de la sociedad.

Ha sido sólo en 2004, a través de la elaboración de "Lineamientos para la Acción en Salud Mental" (Ministerio de Salud), que se ha considerado desarrollar políticas de salud mental como un componente de la salud integral y el desarrollo humano. Teniendo en cuenta que "toda condición que daña la adaptación recíproca entre la persona y su medio, como por ejemplo, la pobreza, la contaminación y la discriminación, constituyen un obstáculo para la salud mental. De manera inversa, toda condición que facilita esta adaptación recíproca, como por ejemplo, la distribución equitativa de la riqueza colectiva, el acceso a una educación de calidad o a un ambiente sano, favorece y mantiene la salud mental(8)".

\section{Bioética}

Como bien resume Lolas(9), "la bioética tiene un largo pasado pero una breve historia": tuvo muchos antecedentes desde tiempos anti- 
guos, pero fue recién en 1971 que el neologismo fue introducido por Van Rensselaer Potter en su libro "Bioethics: Bridge to the future", denominando algo así como una combinación entre conocimientos biológicos y derechos humanos, y dándole luego una acepción de ética global, pero queriendo a la vez alejarse de la ética tradicional.

Gracia Guillén menciona que, en sus inicios, la bioética estuvo unida al desarrollo de la democracia y los derechos humanos(10), pero, en el transcurso de su desarrollo, se ligó más a la medicina y ciencias afines: "la bioética es un intento de lograr procedimientos seculares para formular, analizar y ojalá atenuar los dilemas que plantea la moderna investigación médica y biológica, la asistencia sanitaria y la preservación del medio ambiente"(11).

En esta misma dirección, Llanos ${ }^{1}$ la define como "algo más que los problemas éticos de la práctica médica”, y en otro párrafo explica: "es el conjunto de conocimientos científicos que estudian la transformación tecnológica de la medicina y es, además, la respuesta racional a los problemas morales, políticos y sociales que plantean las formas de atención a la salud humana, con la única finalidad de producir beneficio en las intervenciones biomédicas". Sin embargo, "su campo se ha ido ensanchando y actualmente evoluciona hacia una mayor imbricación con las humanidades y las ciencias psicológicas y sociales"(11, p.73).

\section{Cruce de caminos}

Podemos advertir entonces que, al ampliarse las definiciones y alcances de estos tres conceptos, se han encontrado en el terreno psicológico, sociológico y cultural, formando en la actualidad parte de la vida diaria, del

1 Llanos R. (1998) "Historia de la Bioética en el Perú en el siglo XX". En "Artículos". Archivo personal del autor. hacer y del pensar, del desarrollo individual y social de toda persona. Ello permite evaluar las interacciones de estos factores o las carencias en cada dimensión de la persona, en este caso de la mujer.

Sería muy extenso analizar todas las dimensiones de salud mental que implica el concepto de género, pero haremos algunos alcances sobre el trastorno depresivo, basándonos en los datos del Estudio Epidemiológico Metropolitano de Salud Mental 2002(12), realizado en Lima, Perú.

Planteamos la existencia de problemas y malestares propios de la mujer que devienen de particularidades físicas, funciones biológicas, roles y responsabilidades durante las distintas etapas de su vida y que son inherentes a su género. Por ejemplo, las mujeres tienen tasas más altas de depresión que los hombres, causadas por una serie de factores biológicos y culturales. Las fluctuaciones hormonales juegan un papel importante en la disforia premenstrual o en la depresión post parto. La alteración de la imagen corporal durante el embarazo y su incertidumbre frente a su recuperación son motivos de ansiedad. También la preocupación por la normalidad y salud del feto y el temor de ponerlo en peligro pueden ser abrumadores. Por otro lado, muchas mujeres experimentan diversas molestias y desórdenes emocionales, tanto durante el embarazo como durante el puerperio(13).

A través del estudio epidemiológico(12, p.98) en el que se encuestó a 1.838 "mujeres unidas", mayores de 15 años, apreciamos que el trastorno más frecuente es el estado depresivo, con una prevalencia a seis meses de $16,3 \%$, seguido por una a seis meses de depresión mayor en $15,4 \%$ y por una actual de depresión mayor

2 Casada o con pareja o alguna vez unida a pareja, jefa del hogar o pareja de jefe del hogar. 
en $11,4 \%$. El pensamiento de índole suicida ha sido significativamente mayor comparado con el varón, tanto en la prevalencia de vida $(42,3 \%)$ como en la prevalencia anual $(12,7 \%)$, siendo la de vida de $8,1 \%$ frente a un 5,2\% del adulto masculino.

Estos altos índices de depresión en las mujeres no se relacionan sólo con lo biológico. También en el aspecto psicológico vemos que existe una serie de comportamientos inadecuados que pueden generarlos; por ejemplo, durante el período de enamoramiento de la pareja se encuentran comportamientos tales como: celos (50\%), actitudes machistas (36,8\%), mucho control por parte de la pareja $(21,7 \%)$, descuido por el consumo de alcohol $(21,1 \%)$ e infidelidad $(19,1 \%)$, entre otros.

Al hacer una estimación de estos tratos inadecuados por su actual o última pareja en mujeres unidas, la prevalencia asciende a un $69,6 \%$. Para determinar abuso hacia la mujer se utilizó una submuestra (el 80,4\% de la muestra total) que tenía pareja actual y, en ellas, la prevalencia de vida de algún tipo de abuso fue de $47,0 \%$ : insultos (41,9\%), abuso físico $(28,6 \%)$, humillaciones (16\%), abandono (12\%) y abuso sexual $(9,6 \%)$. Ello revela un alto índice de violencia hacia la mujer y resalta su condición de vulnerabilidad.

Si, por el contrario, buscamos en el área social factores de protección o seguridad, las mujeres no confían o confían poco en las autoridades policiales $(68,5 \%)$ y aún menos en las autoridades políticas $(92,7 \%)$.

La ocurrencia de la violencia física y sexual se produce muchas veces dentro del ámbito doméstico o escolar y proviene de alguien del sexo masculino cercano a la víctima. Sin embargo, el impacto que tiene sobre la vida de las mujeres trasciende el ámbito familiar privado, ya que involucra a diversos agentes públicos, tales como policía, trabajadores de salud y encargados de la justicia, entre otros. Pese a ello, durante muchos años se ha pretendido abordar el tema como un asunto privado que se soluciona solamente entre las partes involucradas, y se niega su carácter de violación de derechos humanos, ante la cual deben existir sanciones para el agresor y reparaciones para la víctima, $\mathrm{y}$ en la que el Estado tiene responsabilidades ineludibles(14).

Deberían analizarse las diversas dimensiones de la vida diaria de la mujer, pues es ahí donde se debe actuar-sobre la base de los principios de la bioética-y preparar el campo propicio para producir salud mental.

En conclusión, sugerimos trabajar sobre los siguientes principios:

\section{Respeto a la persona}

- Respeto a la vida de la mujer.

- Defender su dignidad y su valor como persona.

- Adoptar medidas legislativas que prohíban toda discriminación contra ella.

- Eliminar prejuicios sobre su inferioridad.

- Suprimir la trata de mujeres y la explotación de la prostitución.

- Elección del cónyuge por libre albedrío y matrimonio con pleno consentimiento.

- Defender los derechos de la mujer y facilitar su acceso a todos los niveles e instancias de toma de decisiones.

- Defender su derecho a no ser sometida a tratos crueles o degradantes. 


\section{Beneficencia}

- Acceso a alimentación adecuada de acuerdo con los ciclos de vida y condiciones especiales como el embarazo.

- Promover la prevención y un sistema oportuno y de calidad para el cuidado de la salud de la mujer.

- Protegerla durante el embarazo, con atención médica e información sobre planificación familiar.

- Prevenir y erradicar la violencia física, sexual y psicológica contra las mujeres.

\section{Justicia}

- Igualdad de derechos, oportunidades y responsabilidades, fomentando la redistri- bución de roles, en los cuales las mujeres no sólo estén relegadas a lo privado mientras los hombres dominen en lo público.

- Erradicar el analfabetismo y lograr el acceso equitativo y no discriminatorio a la educación.

- Facilitar su acceso a puestos de responsabilidad que ofrezcan la posibilidad de inspirar las políticas de las naciones y promover soluciones innovadoras para los problemas económicos y sociales.

Al sentar las bases de una sociedad sobre los principios de la bioética, estaremos protegiendo la salud mental de nuestra población y permitiendo que las personas, de acuerdo con su género, se desarrollen en un ambiente armónico, equilibrando lo biológico, psicológico y social.

\section{Referencias}

1. Hurtado Gálvez JM. La mujer social y la mujer histórica. El Catoblepas 2003; 15:18. [Sitio en Internet] Disponible en http://www.nodulo.org/ec/2003/n015p18.htm Último acceso en octubre de 2006.

2. Real Academia Española. Diccionario de la Lengua Española. Vigésima segunda edición; 2001.

3. Varela N. Feminismo para principiantes. México: Ediciones B; 2005: 182.

4. Guerra R. Reflexiones sobre la condición femenina y el fundamento antropológico de la diferenciación sexual. Medicina y Ética 1996; VII(49).

5. Scott JW. El género: una categoría útil para el análisis histórico. [Documento en Internet] Disponible en http://www.cholonautas.edu.pe/modulo/upload/scott.pdf Acceso en octubre 2006.

6. Género y Salud. [Sitio en Internet] Disponible en http://www.diassere.org.pe/gs.html Último acceso en octubre de 2006.

7. Llanos R. Bioética en psiquiatría y psicología: Importancia y proyección en medicina y ciencias de la conducta. Acta Médica Peruana 2001; XVIII: 3-4.

8. Ministerio de Salud. Lineamientos para la acción en salud mental. Lima: Comité Nacional de Salud Mental; 2004.

9. Lolas F. Rehistoriar la bioética en Latinoamérica. La contribución de James Drane. Acta Bioethica 2005; 11(2): 162. 
10. Gracia D. Introducción a la bioética médica. Boletín de la Oficina Sanitaria Panamericana 1990; 108(5-6): 374-378.

11. Lolas F. Bioética. El diálogo moral en las ciencias de la vida. Santiago de Chile: Mediterráneo; 2001.

12. Instituto Especializado en Salud Mental. Estudio Epidemiológico Metropolitano en Salud Mental 2002. Informe General. Anales de Salud Mental 2002; XVIII(1-2).

13. Rondón M. Trastornos depresivos del embarazo y el puerperio. Acta Médica Peruana 2005; XXII(1).

14. Tristán F. Violencia Sexual. [Sitio en Internet] Disponible en http://www.flora.org.pe/violencia\%20sexual. htm Último acceso en octubre de 2006. 